\title{
Trigeminal Neuralgia: Outcomes after Gamma Knife Radiosurgery
}

\author{
Henri Knafo, Brendan Kenny, David Mathieu
}

\begin{abstract}
Background: Trigeminal neuralgia (TN) often remains difficult to treat despite multiple available medications, and can severely impact on the quality of life of affected patients. Gamma knife radiosurgery has recently emerged as a minimally-invasive alternative to surgery for patients suffering from drug-resistant TN. The goal of this study was to report the short-term efficacy of gamma knife radiosurgery for TN and assess its impact on the quality of life of patients treated in the first 18 months of our experience. Methods: Patients with medically-refractory TN or with unacceptable drug side effects were considered for radiosurgery. A maximum dose of 80 Gy was administered to the affected nerve using a single 4-mm isocenter. Follow-up assessments were made at 2, 4 and 6 months, with evaluation of pain relief, drug reduction and quality of life. Factors impacting treatment response were assessed using Cox regression analysis. Results: A total of 67 patients were treated. Significant pain relief was seen in $77.6 \%$ of patients, including $32.6 \%$ who became pain-free. Patients were able to discontinue all medications in $34.3 \%$ or reduce drug intake by more than $50 \%$ in an additional $28.4 \%$ of cases. No variable was found to predict pain relief although older age ( $>66$ years) approached statistical significance. Sensory side effects were seen in $14.9 \%$ of patients. Quality of life improved in the majority of patients after radiosurgery. Conclusions: Gamma knife radiosurgery is a safe and effective management alternative for trigeminal neuralgia, providing good or excellent pain relief and improvement in quality of life in the majority of patients with few side effects.
\end{abstract}

RÉSUMÉ: Névralgie du trijumeau : résultats thérapeutiques après la radiochirurgie par Gamma Knife. Contexte : La névralgie du trijumeau (NT) peut avoir in impact important sur la qualité de vie des patients qui en souffrent. Même si plusieurs médicaments sont maintenant disponibles, elle demeure difficile à traiter. La radiochirurgie par Gamma Knife constitue une nouvelle option thérapeutique chez les patients souffrant d'une NT résistante au traitement médicamenteux. Le but de cette étude était de rapporter l'efficacité à court terme de la radiochirurgie par Gamma Knife chez ces patients et d'évaluer son impact sur leur qualité de vie au cours des 18 premiers mois de notre utilisation de cette technique. Méthodes : Nous avons choisi des patients dont la NT était réfractaire au traitement médical ou qui présentaient des effets secondaires importants. Une dose maximale de 80 Gy a été administrée au niveau du nerf atteint au moyen d'un seul isocentre de $4 \mathrm{~mm}$. Au cours du suivi, une évaluation du degré de soulagement de la douleur, de la diminution de la prise de médicaments et de la qualité de vie a été faite 2, 4 et 6 mois après le traitement. Les facteurs qui influençaient la réponse au traitement ont été évalués par une analyse de régression de Cox. Résultats : Soixante-sept patients ont été traités. Une diminution significative de la douleur a été observée chez 77,6\% des patients, dont 32,6\% n'avaient plus de douleur. Certains patients, soit 34,3\%, ont pu cesser toute médication et $28,4 \%$ ont pu diminuer leur prise de médicaments de plus de $50 \%$. Nous n'avons pas identifié de variable pouvant prédire le soulagement de la douleur, bien qu'un âge plus avancé ( $>66$ ans) semble favorable sans toutefois être significatif. Des effets secondaires sensitifs ont été observés chez 14,9\% des patients. La qualité de vie s'est améliorée chez la majorité des patients après la radiochirurgie. Conclusions : La radiochirurgie par Gamma Knife est une option sûre et efficace dans le traitement de la NT et elle apporte un soulagement de la douleur et une amélioration de la qualité de vie chez la majorité des patients tout en provoquant peu d'effets secondaires.

Can. J. Neurol. Sci. 2009; 36: 78-82

Trigeminal neuralgia (TN), also known as "tic douloureux", is a disease characterized by severe "shock-like" episodic facial pain. It is usually unilateral and involves the sensory distribution of a branch of the fifth cranial nerve. ${ }^{1}$ Various triggers may precipitate a pain attack. Idiopathic $\mathrm{TN}$ is postulated to arise from chronic vascular compression of the trigeminal root entry zone by a blood vessel loop, commonly from the superior cerebellar artery. Carbamazepine and other anti-epileptic drugs are the first-line management of choice. However, if medications fail to relieve the pain or produce intolerable side effects, several neurosurgical procedures can be considered. Microvascular decompression (MVD) aims at alleviating neurovascular compression and has the best potential for long-term relief or cure of TN pain. However, there is a $2 \%-3 \%$ risk of serious complications, including cranial nerve damage, post-operative infection and cerebrospinal fluid (CSF) leak. ${ }^{2}$ Percutaneous destructive procedures are alternatives to MVD that are aimed at

From the Division of Neurosurgery/Radiosurgery, Department of Surgery, Centre Hospitalier Universitaire de Sherbrooke, Université de Sherbrooke, Sherbrooke, Quebec, Canada.

Received September 7, 2007. Final Revisions Submitted July 11, 2008. Correspondence to: David Mathieu, Division of Neurosurgery/Radiosurgery, Centre Hospitalier Universitaire de Sherbrooke, 3001, 12e avenue Nord, Sherbrooke, Quebec, J1H 5N4, Canada. 
damaging the trigeminal nerve (rhizotomy), usually at the Gasserian ganglion, to reduce pain transmission. The long-term success is dependent upon some degree of permanent facial numbness, and there is an associated risk of causing painful dysesthesia or anaesthesia dolorosa. ${ }^{3}$ Gamma knife radiosurgery (GKRS) has recently emerged as a minimally-invasive alternative to percutaneous procedures. Many studies have demonstrated significant long-term improve-ment for patients undergoing radiosurgery for TN. Kondziolka et al reported improvement in $75.4 \%$ of patients after a median follow-up of 33 months, with $55.8 \%$ still having complete or partial pain relief at five years post-radiosurgery. ${ }^{4}$ Another study, by Petit et al, included 112 patients and found that radiosurgery provided significant pain relief and improved quality of life (QOL) in the majority of patients treated for $\mathrm{TN}$, with few bothersome side effects. 5

Gamma knife radiosurgery is offered as a management alternative to $\mathrm{TN}$ patients at the Centre Hospitalier Universitaire de Sherbrooke (CHUS) since August 2004. The goal of this study was to report the efficacy of radiosurgery for patients suffering from intractable $\mathrm{TN}$ in our center and to assess its impact on the quality of life of those patients at six months or more after radiosurgery.

\section{Materials ANd Methods}

\section{Inclusion criteria}

This study included 67 consecutive TN patients treated between August 2004 and March 2006 at our center. Data was collected prospectively. Eligible patients included those with typical trigeminal neuralgia and suboptimal pain relief despite adequate medication, and patients with good relief but bothersome side effects from medication. Radiosurgery was offered either as primary therapy, or after failed MVD or percutaneous rhizotomy. Patients suffering from TN secondary to multiple sclerosis (MS), brainstem stroke, post-herpetic neuralgia and other atypical facial pain were excluded from this study. Every patient was followed for at least six months.

\section{Radiosurgery protocol}

Informed consent for the procedure was obtained with the patient and family members. The Leksell $G$ frame (Elekta Instruments Inc., Atlanta, GA) was installed under local anaesthesia using a mixture of $2 \%$ lidocaine and $0.25 \%$ bupivacaine. A 1-mm thick axial Magnetization prepared rapid gradient echo (MPRAGE) MRI sequence covering the whole head was obtained for treatment planning. A CT cisternogram was used in cases where MRI was contra-indicated. Image transfer from MRI or CT to the planning workstation was done via Ethernet. Leksell GammaPlan software ${ }^{\circledR}$ (Elekta Instruments Inc., Atlanta, GA) was used for dose planning, which was performed jointly by the attending neurosurgeon, radiation oncologist and medical physicist. A maximum dose of 80 Gy was administered to the cisternal portion of the trigeminal nerve at the root entry zone, using a single 4-mm isocenter (Figure 1). Irradiation was performed using a Leksell Gamma knife model $\mathrm{C}$ or 4C (Elekta Instruments, Atlanta, GA). Volumes of brainstem receiving a dosage of 12 Gy or more were calculated. After irradiation, the stereotactic frame was removed and patients were observed for at least 30 minutes prior to their departure.

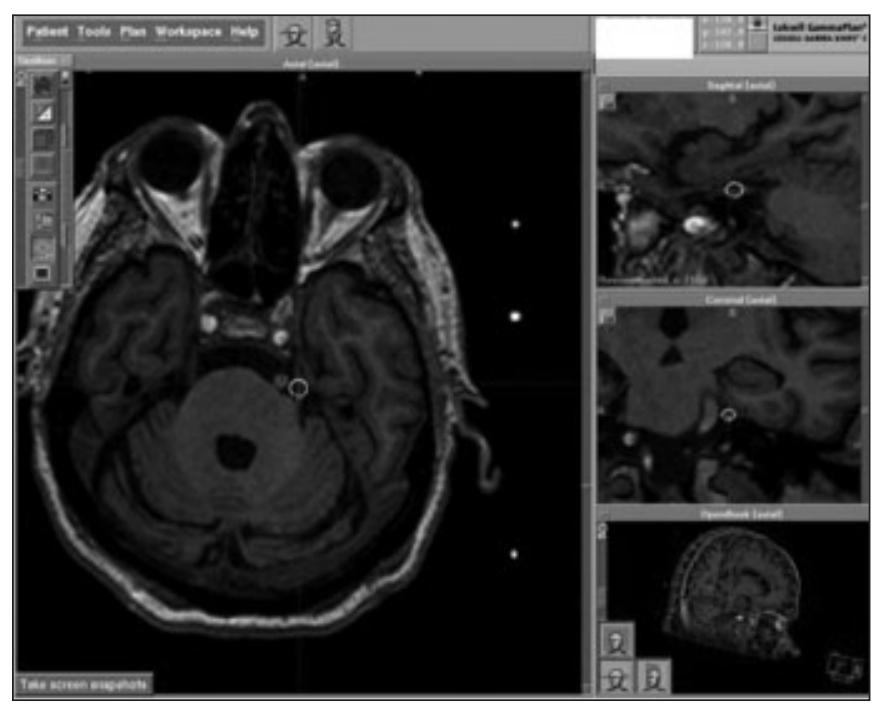

Figure 1: Leksell GammaPlan snapshot demonstrating a typical radiosurgery plan targeting the cisternal portion of the left trigeminal nerve at the root entry zone using a single 4-mm isocenter.

\section{Follow-up}

Follow-up appointments were scheduled at two, four and six month post-radiosurgery, either by phone or at the outpatient clinic. A standardized questionnaire, evaluating pain improvement, side effects, and overall patient satisfaction, was administered and the information was prospectively entered in our database. Patients were asked to assess pain improvement after treatment on a scale of $0 \%$ to $100 \%$. Poor outcome was defined as less than $50 \%$ improvement and good outcome, between $50 \%$ and $99 \%$ improvement. Excellent outcome was attained if patients became pain-free. Quality of life was evaluated via a locally-designed scale (Table 1).

\section{Statistical analysis}

Statistical analysis was performed using a commercially available software package (SPSS version 13.0; SPSS Inc.,

Table 1: Trigeminal neuralgia quality of life assessment scale

\section{Score Description}

1 Go to work normally, normal daily activities, normal social life, pain free or almost pain free

Feels well but has to restrain some activities on some occasions

3 Has to restrain selected basic daily activities because of pain or medication, but remains functional

Patient is debilitated because of severe pain or medication side effects. Impaired talking, tooth brushing, chewing or shaving 
Chicago, IL). Using the Cox proportional hazards model, forward and backward conditional analysis were performed to assess the impact of different variables on treatment outcome, and covariate means calculated. Quality of life prior and after treatment was compared using the Mcnemar test. Probability values less than 0.05 were considered significant.

\section{RESULTS}

\section{Patient population and procedures}

Seventy-four patients had radiosurgery for $\mathrm{TN}$ in our institution during the study period. Seven patients treated for MS-induced TN were excluded from this analysis, thus the study group consisted in 67 patients. The mean age was 66.7 years (range, 20-87 years); $35(52.2 \%)$ were men and $32(47.8 \%)$, women. The left and right side were affected in 24 (35.8\%) and $43(64.2 \%)$ patients, respectively. Before radiosurgery, patients used an average of 1.7 different medications (range, 1-4). Carbamazepine and gabapentin were the most frequently used drugs $(56 \%$ and $46 \%$ of patients, respectively). Only one medication was used prior to treatment in $49.3 \%$ of all subjects (Table 2). Severe drug side effects were noted in 19 patients (28.4\%) and consisted mostly of vertigo, drowsiness and dryness of mucosae. Another surgical procedure, either MVD or percutaneous rhizotomy, had previously been performed on 23 patients (34.3\%) (MVD in 17, rhizotomy in 5 and both in 1). Mean total pain duration was 10.9 years (range, 1-33 years). On planning imaging, a vascular loop compressing the trigeminal nerve was identified in $38.8 \%$ of patients. The average treatment duration was 28.8 minutes. The average volume of brainstem being irradiated with more than 12 Gy was $59.1 \pm 32.9 \mathrm{~mm}^{3}$.

\section{Pain relief after radiosurgery}

Patients were followed for an average of 255 days (range, 174-337 days). Questionnaires were completed at the clinic in $13.4 \%$ and by phone in $86.6 \%$ of evaluations. An average improvement of $64.4 \%, 69.1 \%$, and $69.8 \%$ in the intensity of pain was seen at two, four and six months, respectively, following radiosurgery. At two, four and six months, 31.3\%, $35.8 \%$, $32.6 \%$ of patients, respectively, were pain-free. Significant pain relief (good and excellent outcomes) was attained in $77.6 \%$ of patients after six months. No effect was noted in $14.9 \%$ of patients at two and four months and $13.4 \%$ at

Table 2: Medications used by patients prior to radiosurgery

\begin{tabular}{ll}
\hline Different medications used & Patients (\%) \\
0 & $1(1.5)$ \\
1 & $33(49.3)$ \\
2 & $23(34.3)$ \\
3 & $9(13.4)$ \\
4 or more & $1(1.5)$ \\
\hline
\end{tabular}

Table 3: Pain relief outcome after radiosurgery

\begin{tabular}{llll}
\hline Outcome & 2 months & 4 months & 6 months \\
No improvement & $14.9 \%$ & $14.9 \%$ & $13.4 \%$ \\
Weak & $11.9 \%$ & $7.5 \%$ & $9.0 \%$ \\
Good & $41.8 \%$ & $41.8 \%$ & $44.8 \%$ \\
Excellent (pain free) & $31.3 \%$ & $35.8 \%$ & $32.8 \%$ \\
\hline
\end{tabular}

six months. Table 3 reports treatment outcomes at two, four and six months of follow-up. After radiosurgery, $34.3 \%$ of patients were able to discontinue all pain medications, and $28.4 \%$ significantly diminished drug intake ( $>50 \%$ reduction). Among pain-free patients, $29.9 \%$ did not want to stop medication because of fear of pain recurrence.

No variable was found to significantly impact pain relief on Cox regression analysis, although older age ( $>66$ years) approached statistical significance. Table 4 reports the different variables studied and associated $\mathrm{p}$ values.

\section{Quality of life assessment}

The mean QOL score was $3.31 \pm 0.80$ before radiosurgery and $2.46 \pm 0.89$ after treatment. There was a clear trend toward improvement with most patients attaining class 1 after treatment (Figure 2). Class 4 QOL was present in $17.9 \%$ of patients before radiosurgery, and only $1.5 \%$ after. Overall, $90 \%$ of patients were very satisfied with the procedure and said they would do it again, considering the outcome they attained.

\section{Side effects}

Ten patients (14.9\%) developed some degree of hypoesthesia and paresthesia in the distribution of the irradiated trigeminal nerve. However, it was considered severe and bothersome in

\section{Table 4: Univariate Cox regression analysis of factors affecting outcome of trigeminal neuralgia after radiosurgery}

Variables studied

Older age (66 years or more) p value

Sex

Affected side

Vascular compression present on MRI

Time length since onset of trigeminal neuralgia

Prior microvascular decompression

Prior percutaneous rhizotomy
0.07

0.28

0.58

0.41

0.82

0.32

0.55 


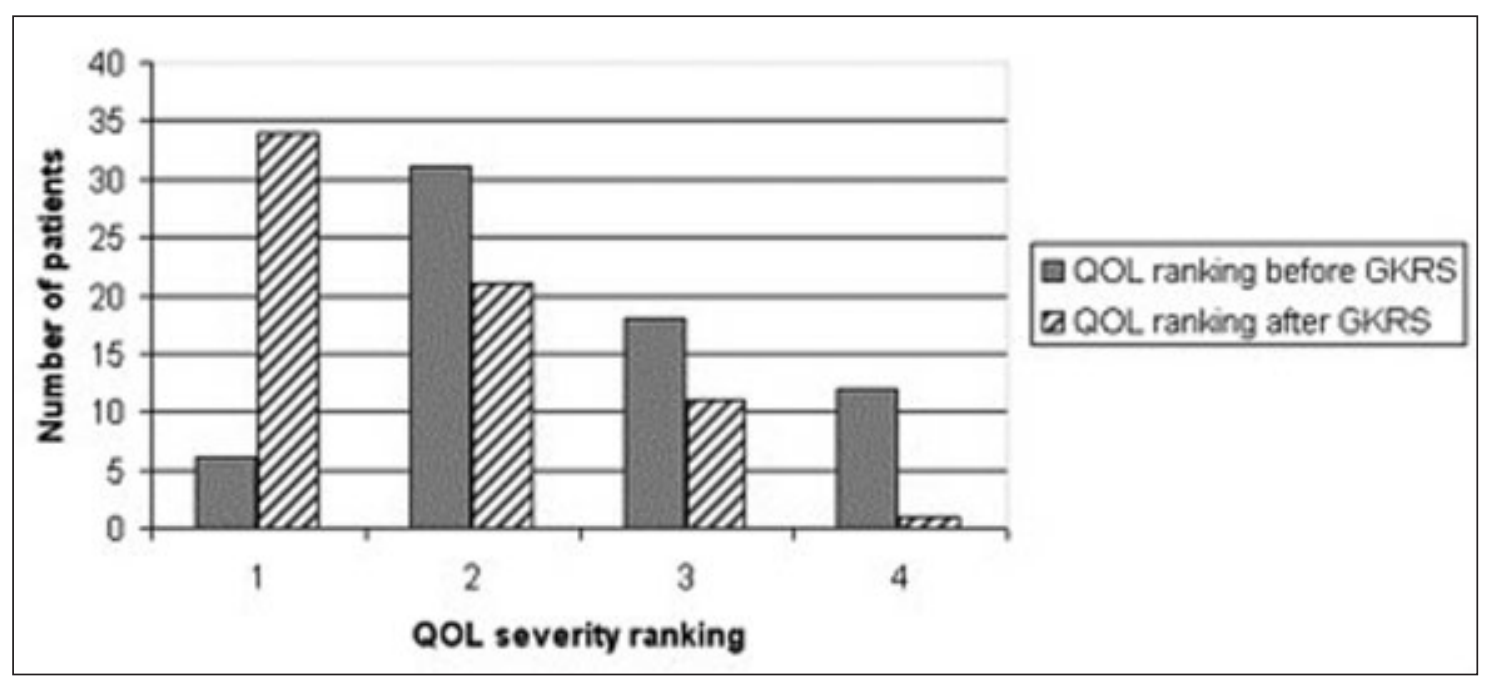

Figure 2: Quality of life of treated patients before and after gamma knife radiosurgery (GKRS) for trigeminal neuralgia at six months of follow-up.

only one patient. No other complication occurred. No variable, including the volume of brainstem receiving more than $12 \mathrm{~Gy}$, was found to predict the occurrence of side effects.

\section{Discussion}

Gamma knife radiosurgery has recently emerged as a minimally-invasive management alternative for patients affected with trigeminal neuralgia. ${ }^{6}$ In this study, we wanted to assess the short-term efficacy of this modality in our center, which was the second gamma knife unit to open in Canada, and compare it to published results.

\section{Pain relief}

The clinical outcome of $220 \mathrm{TN}$ patients following radiosurgery was assessed by Kondziolka et al ${ }^{4}$ Complete pain relief was obtained in $64.9 \%$ and $75.4 \%$ of patients after a follow-up of 6 and 33 months, respectively. After 12 months, Regis et al reported that 83 out of 100 patients were pain-free by targeting the immediate retrogasserian cisternal portion of the fifth cranial nerve. ${ }^{7}$ Among 117 consecutive patients who underwent gamma knife radiosurgery for TN, Pollock et al reported that $57 \%$ were pain-free at one year and 55\% at three years of follow-up. Most of these patients (58\%) had previous unsuccessful surgery (either MVD, percutaneous rhizotomy or peripheral neurectomy) before radiosurgery. Patients without prior surgery had a better outcome (67\% pain-free) at three years. ${ }^{8}$ In another study, by Shaya et al, $40 \%$ of patients had excellent pain control (complete pain relief with at least 50\% reduction in medications) while another $30 \%$ had good control (improvement of $50 \%$ or more)at 14 months after radiosurgery. ${ }^{9}$ In our series, $32.6 \%$ of patients were pain-free and a total of $77.6 \%$ of patients had at least $50 \%$ improvement at six months of follow-up. Urgosik et al noted a median latency period of three months between Gamma knife radiosurgery and pain relief. ${ }^{10}$ Most of our patients had improvement after two months.

\section{Variable affecting treatment outcome}

No factor has universally been reported to impact the outcome of TN radiosurgery although higher doses of radiation may correlate with better facial pain outcomes after radiosurgery for trigeminal neuralgia. ${ }^{11}$ Regis et al reported worse efficacy in patients who had prior surgical procedures for TN relief. Patient without previous surgery had an $88.3 \%$ probability of being pain-free at one year. In comparison, this rate dropped to $75 \%$ for patients who had three or more previous interventions. ${ }^{7}$ Pollock et al also reported that patients who had no prior surgical procedure tended to have better pain relief than those who had prior surgery. ${ }^{8}$ However, Kondziolka et al did not find any difference between patients who had prior surgery and those who did not. ${ }^{12}$ In our study, prior surgical procedure had no impact on the rate of pain relief. The concept of neurovascular compression of the trigeminal root entry zone as the etiology of TN has long been accepted. ${ }^{1}$ A correlation between the identification of a vascular loop in contact with the trigeminal nerve on MRI or MRA and the presence of such compression during MVD for TN has been established. ${ }^{13}$ Although Brisman et al found a better outcome in those patients who had vascular compression on MRI and were never operated on, ${ }^{14}$ most radiosurgery studies reported no significant differences in outcome when comparing patients based on the presence or absence of vascular compression on MRI. ${ }^{15,16}$ In our series, vascular compression on MRI was not a prognostic factor. Although Shaya et al found a higher failure rate among those treated for left-sided $\mathrm{TN}$ (45.5\% compared to $11.1 \%$ for right $\mathrm{TN}),{ }^{9}$ the current literature and our results support the fact that laterality is not a significant prognostic factor of outcome. Sex and total pain duration prior to treatment did not significantly impact outcome in our study. Although Kondziolka et al found no significance for age on treatment outcome, ${ }^{12}$ we found a trend for better pain relief in patients of 66 years or older (complete pain relief in $39.4 \%$ of patients 66 years and older compared to $21.4 \%$ for younger patients at six 
months, $\mathrm{p}=0.07)$. Regis et al also reported that patients younger then 60 years had a lower likelihood of being pain-free $(66.7 \%$ compared with $90.9 \%, \mathrm{p}=0.01){ }^{7}$

\section{Complications}

In most studies, numbness was the most common complaint after radiosurgery and was qualified as minor by most patients. Our results are concordant with this, with only $14.9 \%$ of patients experiencing sensory disturbances, which was bothersome in only one patient. Higher treatment doses have been linked to higher complication rates..$^{11}$ Using a maximum dose of $90 \mathrm{~Gy}$, Nicol et al reported a complication rate of $16.7 \%$, consisting mainly of severe numbness in the trigeminal distribution. Altered taste sensation was present in $9.5 \%$ of subjects. ${ }^{17}$ However, using the same dose, Regis et al reported a total incidence of only $10 \%$ of side, including paresthesia in $6 \%$ of patients and hypesthesia in $4 \% .^{7}$ All side effects were classified as mild by affected patients. This discrepancy between side effects might be related to target selection. Concerns have been raised about the risks of increasing the radiation dose closer to the root entry zone. A relationship between the volume of the brainstem receiving $20 \%$ or more of the maximal dose and an increased incidence of complications has been debated. ${ }^{18}$ Matsuda et al reported a rate of $17.1 \%$ of complications (numbness and hypesthesia) with $7.3 \%$ of patients having conjunctival dryness and discomfort. ${ }^{19}$ The treatment protocol used a proximal target on the nerve and a maximum radiation dose of $80 \mathrm{~Gy}$. Complications were attributed mostly to brainstem injury from the radiation. However, in our patients, we could not identify any relationship between the volume of brainstem receiving more than $12 \mathrm{~Gy}$ and the occurrence of side effects.

\section{Quality of life assessment}

There have been few studies pertaining to QOL assessment following radiosurgery for trigeminal neuralgia. One such study, by Jawahar et al., demonstrated favourable outcomes in terms of QOL after radiosurgery. ${ }^{20}$ Overall patient satisfaction score was $80 \%$, which is similar to our results, parameters to assess pain control were derived from the short-form McGill pain questionnaire. Unfortunately, no tool was specifically designed and standardized to assess QOL in patients with TN. Our homemade QOL rating scale is fairly simple to use and represents patient functional status in everyday life. Using this scale, we observed in our series a significant improvement in QOL at six month or more after radiosurgery (as showed in Figure 2).

Gamma knife radiosurgery is a safe and effective alternative to microvascular decompression or percutaneous rhizotomy for the management of trigeminal neuralgia in patients refusing or unable to undergo these procedures. The short-term improvement observed in our patients is concordant with the literature, with acceptable mild side effects. Older patients may benefit more from the procedure than younger ones. However, uncertainties remain, particularly pertaining to the optimal radiation dose and target, which might be resolved in the future by randomized studies.

\section{REFERENCES}

1. Eller JL, Raslan AM, Burchiel KJ. Trigeminal neuralgia: definition and classification. Neurosurg Focus. 2005;18(5):E3.

2. McLaughlin MR, Jannetta PJ, Clyde BL, Subach BR, Comey CH, Resnick DK. Microvascular decompression of cranial nerves: lessons learned after 4400 operations. J Neurosurg. 1999;90(1): 1-8.

3. Pagni CA, Lanotte M, Canavero S. How frequent is anesthesia dolorosa following spinal posterior rhizotomy? A retrospective analysis of fifteen patients. Pain. 1993;54(3):323-7.

4. Kondziolka D, Lunsford LD, Flickinger JC. Stereotactic radiosurgery for the treatment of trigeminal neuralgia. Clin J Pain. 2002;18(1):42-7

5. Petit JH, Herman JM, Nagda S, DiBiase SJ, Chin LS. Radiosurgical treatment of trigeminal neuralgia: evaluating quality of life and treatment outcomes. Int J Radiat Oncol Biol Phys. 2003;56(4): 1147-53.

6. McNatt SA, Yu C, Giannotta SL, Zee CS, Apuzzo ML, Petrovich Z. Gamma knife radiosurgery for trigeminal neuralgia. Neurosurgery. 2005(6);56:1295-303.

7. Regis J, Metellus P, Hayashi M, Roussel P, Donnet A, Bille-Turc F. Prospective controlled trial of gamma knife surgery for essential trigeminal neuralgia. J Neurosurg. 2006;104(6):913-24.

8. Pollock BE, Phuong LK, Gorman DA, Foote RL, Stafford SL. Stereotactic radiosurgery for idiopathic trigeminal neuralgia. J Neurosurg. 2002;97(2):347-53.

9. Shaya M, Jawahar A, Caldito G, Sin A, Willis BK, Nanda A. Gamma knife radiosurgery for trigeminal neuralgia: a study of predictors of success, efficacy, safety, and outcome at LSUHSC. Surg Neurol. 2004;61(6):529-35.

10. Urgosik D, Vymazal J, Vladyka V, Liscak R. Treatment of postherpetic trigeminal neuralgia with the gamma knife. J Neurosurg. 2000;93 Suppl 3:165-8.

11. Pollock BE, Phuong LK, Foote RL, Stafford SL, Gorman DA. High-dose trigeminal neuralgia radiosurgery associated with increased risk of trigeminal nerve dysfunction. Neurosurgery. 2001;49(1):58-64.

12. Kondziolka D, Lunsford LD, Flickinger JC, Young RF, Vermeulen $\mathrm{S}$, Duma CM, et al. Stereotactic radiosurgery for trigeminal neuralgia: a multiinstitutional study using the gamma unit. J Neurosurg. 1996;84(6):940-5.

13. Sens MA, Higer HP. MRI of trigeminal neuralgia: initial clinical results in patients with vascular compression of the trigeminal nerve. Neurosurg Rev. 1991;14(1):69-73.

14. Brisman R, Khandji AG, Mooij RB. Trigeminal nerve-blood vessel relationship as revealed by high-resolution magnetic resonance imaging and its effect on pain relief after Gamma knife radiosurgery for trigeminal neuralgia. Neurosurgery. 2002;50(6): 1261-7.

15. Cheuk AV, Chin LS, Petit JH, Herman JM, Fang HB, Regine WF. Gamma knife surgery for trigeminal neuralgia: outcome, imaging, and brainstem correlates. Int J Radiat Oncol Biol Phys. 2004;60(2):537-41.

16. Sheehan J, Pan HC, Stroila M, Steiner L. Gamma knife surgery for trigeminal neuralgia: outcomes and prognostic factors. J Neurosurg. 2005;102(3):434-41.

17. Nicol B, Regine WF, Courtney C, Meigooni A, Sanders M, Young B. Gamma knife radiosurgery using 90 Gy for trigeminal neuralgia. J Neurosurg. 2000;93 Suppl 3:152-4.

18. Massager N, Nissim O, Murata N, Devriendt D, Desmedt F, Vanderlinden B, et al. Effect of beam channel plugging on the outcome of gamma knife radiosurgery for trigeminal neuralgia. Int J Radiat Oncol Biol Phys. 2006;65(4):1200-5.

19. Matsuda S, Serizawa T, Sato M, Ono J. Gamma knife radiosurgery for trigeminal neuralgia: the dry-eye complication. J Neurosurg. 2002;97 Suppl 5:525-8.

20. Jawahar A, Wadhwa R, Berk C, Caldito G, DeLaune A, Ampil F, et al. Assessment of pain control, quality of life, and predictors of success after gamma knife surgery for the treatment of trigeminal neuralgia. Neurosurg Focus. 2005;18(5):E8. 